\title{
SINTESIS DAN KARAKTERISASI CARBON NANOTUBE (CNt) DARI ARANG KAYU JATI SERTA PEMANFAATANNYA SEBAGAI BAHAN AKTIF ANTIBAKTERI
}

\author{
Agung Rimayanto Gintu ${ }^{\mathrm{a}}$, Dhanang Puspita ${ }^{\mathrm{b}}$ \\ ${ }^{a}$ Magister Biologi, Fakultas Biologi, Unuversitas Kristen Satya Wacana Jln Diponegoro No.52-60 Salatiga (50711), \\ Jawa Tengah \\ ${ }^{b}$ Fakultas Kedokteran dan Ilmu Kesehatan, Universitas Kristen Satya Wacana, Jln Kartini No.11A Salatiga (50714), \\ Jawa Tengah \\ email: agunggintu911@gmail.com; agunggintu911@yahoo.com
}

Received 8 October 2020

Accepted 5 December 2020

\begin{abstract}
Abstrak
Karbon Nanotube (CNt) merupakan bahan aktif antibakteri yang disintesis dari arang atau arang aktif. Pada penelitian ini dilakukan sintesis CNt dari arang kayu jati menggunakan asam nitrat dan sonikasi. Rendemen sintesis CNt diperoleh 37,6555 $\pm 0,8038 \%$. Karakterisasi CNt menunjukkan densitas 1,0145 $\pm 0,0037 \mathrm{~g} / \mathrm{cc}$; Viscositas mutlak 1,06 $\pm 0,0245$ P.a; Bobot molekul $0,0007 \pm 0,00002 \mathrm{~g} / \mathrm{mol}$. Dilakukan modifikasi CNt untuk menambah stabilitas serta kekuatan interaksi dengan pengikatan logam dan pencampuran dengan komponen lain menghasilkan CNt$\mathrm{Ag}, \mathrm{CNt}-\mathrm{Cu}, \mathrm{CNt}-\mathrm{Fe}(\mathrm{II}), \mathrm{CNt}-\mathrm{Fe}(\mathrm{III}), \mathrm{CNt}-\mathrm{Mg}, \mathrm{CNt}-\mathrm{Zn}, \mathrm{CNt}-\mathrm{HAp}, \mathrm{CNt}-\mathrm{Kitosan}$ dan CNt-Nano Kitosan. Pengukuran densitas komposit secara berurutan menunjukkan 1,0072 $\pm 0,0055$; $1,0086 \pm 0,0040 ; 1,0060 \pm 0,0013 ; 1,0159 \pm 0,0042 ; 0,9970 \pm 0,0008 ; 1,0013 \pm 0,0013 ; 1,0008 \pm 0,0010$; $0,9992 \pm 0,0019$; dan $1,0084 \pm 0,0002 \mathrm{~g} / \mathrm{cc}$. Sementara itu viscositas mutlaknya secara berurutan adalah $0,66 \pm 0,0400 ; \quad 0,56 \pm 0,0400 ; \quad 0,76 \pm 0,0400 ; \quad 0,82 \pm 0,0200 ; \quad 0,64 \pm 0,0400 ; \quad 0,60 \pm 0,0447$;

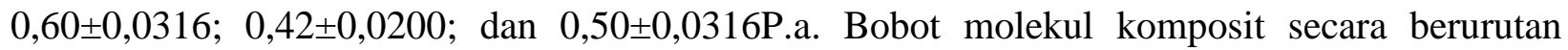
menunjukkan $\quad 0,0007 \pm 0,00004 ; \quad 0,0007 \pm 0,00003 ; \quad 0,0007 \pm 0,000001 ; \quad 0,0007 \pm 0,00003$; $0,0007 \pm 0,000005 ; \quad 0,0007 \pm 0,000005 ; \quad 0,0007 \pm 0,000007 ; \quad 0,4343 \pm 0,0207 ; \quad$ dan $0,5170 \pm 0,3270 \mathrm{~g} / \mathrm{mol}$. Hasil pengukuran aktivitas antibakteri terhadap bakteri E.coli menunjukkan hasil modifikasi CNt-HAp dan CNt-Ag menghasilkan daya antiakteri pada kisaran golongan sangat kuat dan $\mathrm{CNt}-\mathrm{Cu}$ pada kisaran kuat.
\end{abstract}

Kata kunci: Arang, Bahan Antibakteri, Karbon Nanotube

\begin{abstract}
Carbone Nanotube (CNt) was one of antibacterial compound synthesized from carbon pr activated carbon. In this study threated the synthesis of CNt from teak charcoal used nitric acid and sonication. The rendement of CNt synthesis showed 37,6555 $\pm 0,8038 \%$. The characterization to the CNt showed density 1,0145 $\pm 0,0037 \mathrm{~g} / \mathrm{cc}$; Absolute Viscosity 1,06 $\pm 0,0245 \mathrm{P}$.a; Molecule weight $0,0007 \pm 0,00002 \mathrm{~g} / \mathrm{mol}$. Threated the modification to the CNt to increase the stabilitation and interaction by metal ions binding and mix with another compounds produced $\mathrm{CNt}-\mathrm{Ag}, \mathrm{CNt}-\mathrm{Cu}$, CNt-Fe(II), CNt-Fe(III), CNt-Mg, CNt-Zn, CNt-HAp, CNt-Chitosan dan CNt-Nano Chitosan. The density measurements of the composites sequentially showed $1,0072 \pm 0,0055 ; 1,0086 \pm 0,0040$; $1,0060 \pm 0,0013 ; 1,0159 \pm 0,0042 ; 0,9970 \pm 0,0008 ; 1,0013 \pm 0,0013 ; 1,0008 \pm 0,0010 ; 0,9992 \pm 0,0019$; and $1,0084 \pm 0,0002 \mathrm{~g} / \mathrm{cc}$. Meanwhile, the absolute viscosity are $0,66 \pm 0,0400 ; 0,56 \pm 0,0400$; $0,76 \pm 0,0400 ; \quad 0,82 \pm 0,0200 ; \quad 0,64 \pm 0,0400 ; \quad 0,60 \pm 0,0447 ; \quad 0,60 \pm 0,0316 ; \quad 0,42 \pm 0,0200 ; \quad$ and
\end{abstract}


$0,50 \pm 0,0316$ P.a respectively. The molecular weight measurements of the composites sequentially showed $\quad 0,0007 \pm 0,00004 ; \quad 0,0007 \pm 0,00003 ; \quad 0,0007 \pm 0,000001 ; \quad 0,0007 \pm 0,00003$; $0,0007 \pm 0,000005 ; \quad 0,0007 \pm 0,000005 ; \quad 0,0007 \pm 0,000007 ; \quad 0,4343 \pm 0,0207 ; \quad$ and $0,5170 \pm 0,3270 \mathrm{~g} / \mathrm{mol}$. The results of antibacterial activity measurements against E.coli bacteria showed that the modified CNt-HAp and CNt-Ag produced the antibacterial activity classified into very strong and $\mathrm{CNt}-\mathrm{Cu}$ classified into strong activity.

Keywords: Antibacterial compounds, Carbon Nanotube, Charcoal

\section{Pendahuluan}

Carbon Nano Tube (CNt) / Karbon Nano berbentuk silinder adalah komponen karbon yang berbentuk tabung berukuran nano dengan rasio perbandingan panjang:lebar 132.000.000:1, lebih besar dibanding material lainnya. Nanotube termasuk salah satu anggota struktural fullerene. Nama nanotube berasal dari bentuk yang panjang dan berlubang dengan dinding yang dibentuk oleh lembaran satu atom karbon tebal disebut graphene. Lembaran karbon ini digulung pada diskrit dan sudut tertentu. Nanotube dikategorikan sebagai nanotube berdinding tunggal atau SWNTs dan nanotube berdinding multi (MWNTs). Kebanyakan nanotube berdinding tunggal (SWNT) mempunyai diameter mencapai 1 nanometer dengan lebar tabung dapat mencapai jutaan kalinya. Struktur dari SWNT dapat dikonsepkan dengan membengkokan grafit selebar satu atom yang disebut graphene hingga membentuk silinder. Cara lembaran graphene menggulung dapat dipresentasikan oleh sepasang indeks $(n, m)$. Integral dari $\mathrm{n}$ dan $\mathrm{m}$ menunjukan jumlah vektor satuan sepanjang dua arah dalam sturuktur kisi sarang lebah kristal graphene. Jika $\mathrm{m}=0$, nanotube disebut sebagai nanotube Zig-zag, dan jika $\mathrm{n}=\mathrm{m}$, disebut sebagai nanotube armchair. SWNT sangat penting dari berbagai nanotube karena sebagian besar sifat nanotube berubah secara signifikan mengikuti nilai $(\mathrm{n}, \mathrm{m})$ dan ketergantungan ini bersifat non-monoton. Rentang Energi nanotube dapat bervariasi dari nol sampai sekitar $2 \mathrm{eV}$ dan konduktivitas listriknya dapat menunjukkan perilaku semikonduktor (Venkatesan et al, 2014; Wang et al, 2009). Nanotube secara alami akan menyesuaikan diri membentuk tali yang dipertahankan oleh gaya van der Waals, lebih spesifiknya berupa susunan pi. Dalam terapan Kimia Kuantum khususnya hibridisasi orbital, ikatan kimia dari nanotube terbentuk dari ikatan $\mathrm{sp}^{2}$ mirip dengan grafit. Ikatan ini lebih kuat dibanding ikatan $\mathrm{sp}^{3}$ yang ditemukan di alkana dan berlian. membuat nanotube memiliki sifat kekuatan yang unik (Venkatesan et al, 2014; Wang et al, 2009). CNt dapat diperoleh dari oksidasi asam dan exfolasi lempeng grafit. Karena presentase muatan negatif gugus teroksigenasi seperti Epoxi dan Hydroxyl pada permukaan sama sperti gugus karboksilat, GO akan mudah terdispersi oleh air dalam bentuk lempeng tunggal. GO nanosheets dapat tereduksi membentu grafit selama deoksidasi termal atau reduksi kimiawi. Ukuran lempeng / butiran GO terfragmentasi dapat dikontrol dengan variasi waktu sonikasi. Penelitian acuan menghipotesiskan bahwa mengsonikasi GO dalam asam pekat memperkecil ukuran GO nanoshets menjadi nanofragmen dan senyawa poliaromatik terlarut. Kombinasi vibrasi gelombang sonic dan asam kuat memotong GO nanosheets menjadi fragmen - fragmen yang lebih pendek (Venkatesan et al, 2014; Wang et al, 2009). Molekul silinder karbon sangat bermanfaat dibidang nanoteknologi, 
elektronik, optik dan berbagai bidang ilmu dan teknologi material, karena memiliki konduktifitas termal aupun sifat mekanis dan listrik karbon nanotube dapat diaplikasikan untuk berbagai macam bahan struktur (Venkatesan et al, 2014; Wang et al, 2009).

Tujuan dari penelitian ini adalah mensintesis $\mathrm{CNt}$ dari arang kayu jati menggunakan pelarut $\mathrm{HNO}_{3} 70 \%$ dengan katalis $\mathrm{NaNO}_{3}$ dengan paparan sonic. $\mathrm{CNt}$ hasil sintesis kemudian dimanfaatkan sebagai bahan aktif antibakteri dalam disinfektan.

\section{Metode Penelitian} Alat dan Bahan

Alat yang digunakan pada penelitian ini adalah Moisture analyzer, Brix Refractometer, neraca 4 digit, sonicator, multimeter, dan hot plate. Piranti yang digunakan berupa beaker glas, spatula, cawan petri dan spatula. Bahan Kimia yang digunakan berupa $\mathrm{HNO}_{3}$ pekat (P.A), $\mathrm{NaNO}_{3}, \mathrm{H}_{2} \mathrm{O}_{2}, \mathrm{Cu}$-Acetat, $\mathrm{AgNO}_{3}, \mathrm{FeSO}_{4}$, $\mathrm{FeCl}_{2}, \quad \mathrm{MgCO}_{3}, \quad \mathrm{ZnCl}_{2}$, Aquades, dan aquabides

\section{Karakterisasi Arang Kayu Jati}

Karakterisasi arang kayu jati secara grafimetrik meliputi pengukuran kadar Air, abu, Bahan organic, Karbon dan Silicon (AOAC, 1990; Sulaeman et al, 2005; Sudarmadji et al, 2010).

\section{Sintesis CNt dari Arang}

Sintesis CNt dari arang kayu jati dilakukan menggunakan $\mathrm{HNO}_{3} 70 \%$ dan sonikasi selama 90 menit (Venkatesan et al, 2014; Wang et al, 2009).

\section{Pengukuran Daya Antibakteri CNt}

Daya antibakteri $\mathrm{CNt}$ terhadap bakteri E.coli dilakukan dengan metode tuang permukaan pada medium NA padat
(AOAC, 1990; Suriawiria, 1993; Sulaeman et al, 2005; Sudarmadji et al, 2010)

\section{Hasil dan Pembahasan}

Arang kayu jati dipilih sebagai bahan sintesis CNt karena mudah ditemukan dalam jumlah banyak dengan harga yang murah. Arang juga kaya akan karbon (Campbell \& Jane, 2010; Suriawiria, 1993) sehingga tepat untuk dijadikan sumber atau bahan mentah untuk sintesis menghasilkan CNt. Hasil karakterisasi arang kayu jati ditampilkan pada Tabel 1.

\begin{tabular}{|c|c|c|}
\hline Parameter Kadar & Satuan & $\begin{array}{l}\text { Kadar Terukur } \\
(\bar{X} \pm \mathrm{SE})\end{array}$ \\
\hline Air & $\%$ & $0,6375 \pm 0,0593$ \\
\hline Abu & $\mathrm{g} / \mathrm{g}$ & $0,0358 \pm 0,0007$ \\
\hline Bahan Organik & $\%$ & $95,9777 \pm 0,1448$ \\
\hline Karbon Organik & $\%$ & $55,6670 \pm 0,0840$ \\
\hline Silikon & $\%$ & $86,1904 \pm 0,6909$ \\
\hline Rendemen CNt & $\%$ & $37,6555 \pm 0,8038$ \\
\hline $\begin{array}{c}\text { Yield Reduksi } \\
\text { Materi }\end{array}$ & $\%$ & $62,3445 \pm 0,8038$ \\
\hline
\end{tabular}

Kadar bahan organik yang lebih dari 50\% nya adalah karbon menunjukkan bahwa arang kayu jati merupakan sumber $\mathrm{CNt}$ dengan peluang penerapan yang besar. Hasil sintesis $\mathrm{CNt}$ dari arang kayu jati juga menunjukkan peluang keberhasilan yang cukup menjanjikan yaitu sebesar 37,6555 \pm $0,8038 \%$. Dilakukan karakterisasi fisikokimia terhadap CNt hasil sintesis dari arang kayu jati untuk mengetahui sifat kimiawi $\mathrm{CNt}$ sebagai langkah awal penerapan $\mathrm{CNt}$ sebagai bahan aktif antibakteri. Untuk meningkatkan daya antibakteri CNt dilakukan penambatan logam oksida (doped) serta pencampuran $\mathrm{CNt}$ dengan komponen lain yang juga merupakan bahan antibakteri. Hasil karakterisasi $\mathrm{CNt}$ dan CNt hasil perlakuan ditampilkan pada Tabel 2. 
Tabel 2. Hasil Karakterisasi CNt dan CNt Hasil Perlakuan

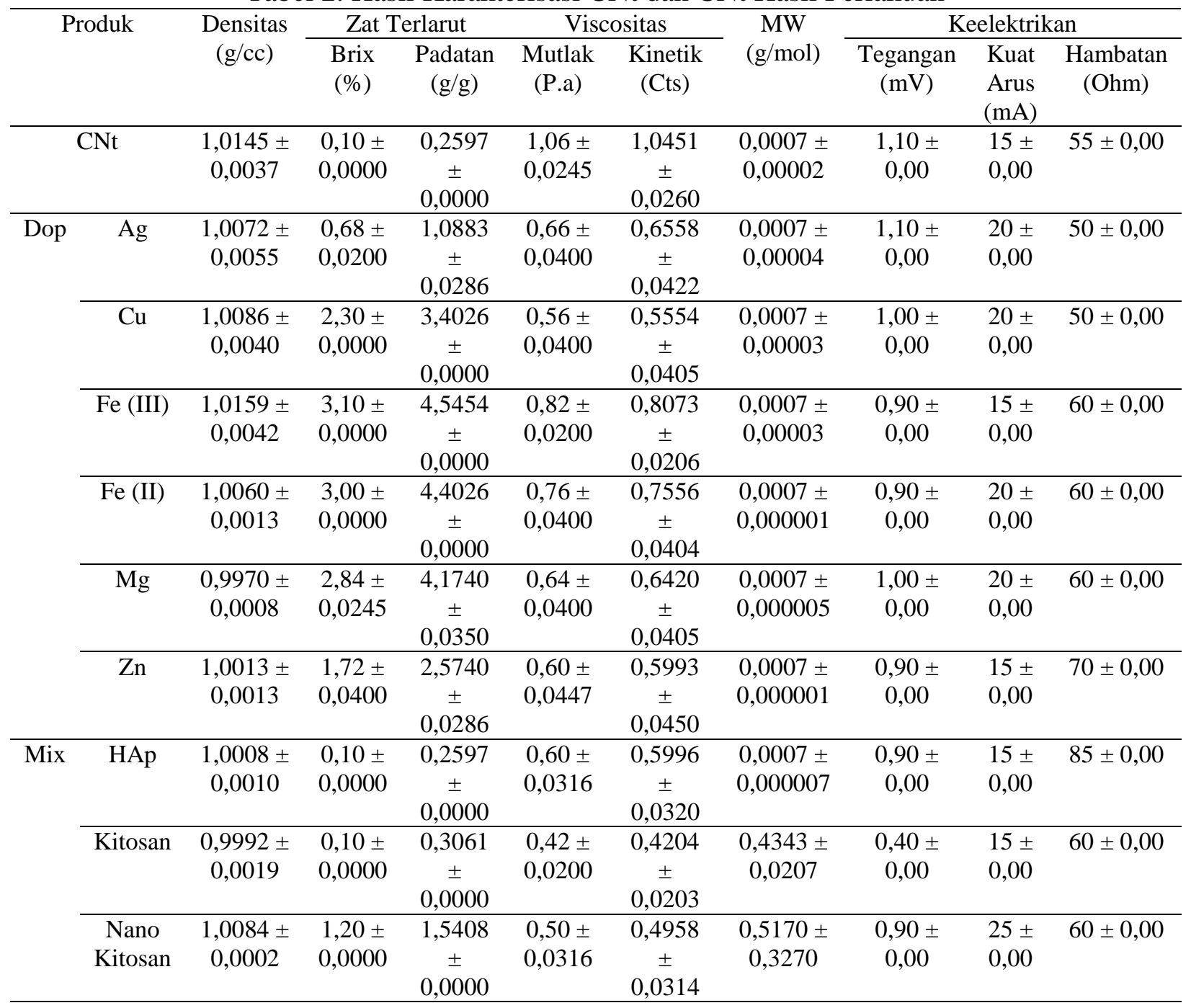

Penambatan logam oksida dan pencampuran dengan komponen antibakteri lain bertujuan untuk meningkatkan daya antibakteri suatu component (Nathanael et al, 2009; Ciobanu et al, 2012; Purnomo, 2014; Ragab et al, 2014) seperti CNt. Logam oksida yang ditambatkan ke CNt merupakan logam oksida yang dapat menimbulkan efek toksik bagi bakteri (Suriawiria, 1993; WHO, 2017) karena dapat mengganggu stabilitas membrane sel (Campbel \& Jane, 2010; Nathanael et al, 2009; Ciobanu et al, 2012; Purnomo, 2014; Ragab et al, 2014). Komponen antibakteri yang digunakan sebagai campuran $\mathrm{CNt}$ adalah komponen atibakteri yang tergolong dalam komponen berdaya antibakteri kuat yaitu Kitosan (Venkatesan et al, 2014) dan Hidroksiapatit (HAp) (Kolmas et al, 2014; Lamkhao et al, 2018; Ragab et al, 2014; Wadu et al, 2017). CNt merupakan daya antibakteri yang baik (Venkatesan et al, 2014) namun masih perlu tambahan untuk meningkatkan stabilitas dan daya antibakteri CNt. Hasil pengukuran daya antibakteri $\mathrm{CNt}$ dan $\mathrm{CNt}$ hasil perlakuan ditampilkan pada Tabel 3. 
Tabel 3. Hasil Pengukuran Daya Antibakteri CNt dan CNt Hasil Perlakuan Terhadap

\begin{tabular}{|c|c|c|c|}
\hline \multicolumn{4}{|c|}{ Bakteri E. coli } \\
\hline & Produk & $\begin{array}{c}\mathrm{DDH} \\
(\mathrm{mm})(\bar{X} \\
\pm \mathrm{SE})\end{array}$ & $\begin{array}{c}\text { Golongan Daya } \\
\text { Antibakteri }\end{array}$ \\
\hline & $\mathrm{CNt}$ & $\begin{array}{l}14 \pm \\
0,00\end{array}$ & Kuat \\
\hline \multirow[t]{6}{*}{ Dop } & $\mathrm{Ag}$ & $\begin{array}{c}17,2 \pm \\
0,00 \\
\end{array}$ & Kuat \\
\hline & $\mathrm{Cu}$ & $\begin{array}{l}17 \pm \\
0,00\end{array}$ & Kuat \\
\hline & $\mathrm{Fe}$ (III) & $\begin{array}{c}15,5 \pm \\
0,00 \\
\end{array}$ & Kuat \\
\hline & $\mathrm{Fe}(\mathrm{II})$ & $\begin{array}{l}11 \pm \\
0,00\end{array}$ & Sedang-Kuat \\
\hline & $\mathrm{Mg}$ & $\begin{array}{l}14 \pm \\
0,00\end{array}$ & Kuat \\
\hline & $\mathrm{Zn}$ & $\begin{array}{l}13 \pm \\
0,00\end{array}$ & Kuat \\
\hline \multirow[t]{3}{*}{ Mix } & HAp & $\begin{array}{l}18 \pm \\
0,00\end{array}$ & Kuat \\
\hline & Kitosan & $\begin{array}{l}15 \pm \\
0,00\end{array}$ & Kuat \\
\hline & $\begin{array}{c}\text { Nano } \\
\text { Kitosan }\end{array}$ & $\begin{array}{l}11 \pm \\
0,00\end{array}$ & Sedang-Kuat \\
\hline
\end{tabular}

Hasil perlakuan sebagian besar menunjukkan bahwa penambatan dan pencampuran terhadap $\mathrm{CNt}$ berhasil meningkatkan daya hambat $\mathrm{CNt}$ terhadap bakteri E. coli. Bakteri E. coli dipilih sebagai bakteri uji karena merupakan bakteri gram negative dengan dinding sel yang tebal (Campbel \& Jane, 2010), bakteri ini juga dipilih karena merupakan bakteri pencemar penyebab gangguan kesehatan (Suriawiria, 1993; WHO, 2017). Pada penambatan menggunakan $\mathrm{Fe}(\mathrm{II})$ dan pencampuran dengan Nano kitosan, terjadi penurunan daya hambat $\mathrm{CNt}$ dari kuat menurun ke skala sedang. Penurunan daya antibakteri ini disebabkan oleh perubahan struktur Carbon Nanotube yang berbentuk silinder / tabung (tube) menjadi lembaran (Sheet) sehingga arang nano tidak bisa sepenuhnya disebut Carbon Nanotube (CNt), tetapi Carbon Nanosheets (CNs) (Gintu et al, 2018). Dalam bentuk lembaran (Sheet), interaksi dengan sel bakteri akan sangat sulit terjadi, bahkan jika terjadipun sangat tidak efektif menimbulkan kematian pada bakteri uji (Gintu et al, 2018).

Penelitian sebelumnya menggunakan komponen CNt terhadap bakteri yang sama melaporkan bahwa CNt tidak menghasilkan daya antibakteri pada konsentrasi 25-50ppm (Gintu et al, 2018). Penyebab tidak dihasilkannya daya antibakteri pada penelitian sebelumnya diperkirakan adalah gejala yang sama yakni perubahan struktur arang dari Nanotube menjadi Nanosheets (Gintu et al, 2018). Berdasarkan hasil pengukuran daya antibakteri $\mathrm{CNt}$ dan $\mathrm{CNt}$ hasil perlakuan dapat disimpulkan bahwa CNt yang disintesis dari arang kayu jati dan $\mathrm{CNt}$ hasil penambatan ion logam dan pencampuran dengan bahan aktif lain memiliki peluang yang besar untuk menjadi bahan aktif antibakteri.

\section{Kesimpulan}

1. Hasil pengukuran daya antibaketri terhadap $\mathrm{CNt}$ dan hasil modifikasi menunjukkan daya antibakteri sangat kuat diperoleh dari komponen CNt-HAp dengan diameter daerah hambat terhadap bakteri E. coli sebesar $18 \pm 0,00 \mathrm{~mm}$. Karakter fisikokimia dari carbon nanotube ini menunjukkan densitas sebesar 1,0008 $\pm 0,0010 \mathrm{~g} / \mathrm{cc}$; viscositas mutlak 0,60 $\pm 0,0316$ P.a; dan bobot molekul 0,0007 $\pm 0,000007 \mathrm{~g} / \mathrm{mol}$. Daya antibakteri lain yang berada pada kisaran sangat kuat diperoleh dari komposit CNt$\mathrm{Ag}$ dengan diameter daerah hambat sebesar 17,2 $\pm 0,00 \mathrm{~mm}$. Komposit ini memiliki karakter fisikokimia dengan menunjukkan densitas sebesar $1,0072 \pm 0,0055 \mathrm{~g} / \mathrm{cc} ;$ viscositas mutlak 0,66 $\pm 0,0400$ P.a; dan bobot molekul $0,0007 \pm 0,00004 \mathrm{~g} / \mathrm{mol}$. Sementara itu daya antibakteri pada kisaran kuat diperoleh dari komposit $\mathrm{CNt}-\mathrm{Cu}$ dengan diameter daerah hambat terhadap bakteri E. coli sebesar $17 \pm 0,00 \mathrm{~mm}$. Komposit $\mathrm{CNt}-\mathrm{Cu}$ menunukkan karakter fisikokimia 
dengan densitas sebesar $1,0086 \pm 0,0040 \mathrm{~g} / \mathrm{cc} ;$ viscositas mutlak 0,56 $\pm 0,0400 \mathrm{P} . \mathrm{a} ;$ dan bobot molekul $0,0007 \pm 0,00003 \mathrm{~g} / \mathrm{mol}$.

2. Hasil pengukuran aktivitas antibakteri terhadap bakteri E.coli menunjukkan semua komposit modifikasi $\mathrm{CNt}$ menghasilkan daya antibakteri pada kisaran sedang hingga sangat kuat sehingga berpeluang besar dimenfaatkan sebagai bahan aktif antibakteri.

\section{Daftar Pustaka}

Association of Official Analytical Chemists. 1990. Official Methods of Analysis $15^{\text {th }}$ Edition. Washington D.C. The United States of America Legally Binding Document.

Campbell, N A; \& Jane, B R. 2010. Biologi Jilid 1. Jakarta. Erlangga. ISBN: 978979-075-688-5.

Ciobanu, C S; Simona, L I; Philipe L C; Liliana, V C; \& Daniela, P. 2012. Antibacterial Activity of Silver Doped Hydroxyapatite Nanoparticles Against Gram positive and Gram Negative Bacteria. Nanoscale Research Letters. http://www.nanoscalereslett.com/conte nt/7/1/324.

Gintu, A R; Imelda, W; Dewi K. A. K. H; Cucun, A R; \& Yohanes, S W. 2018. Sintesa Komposit Kitosan dan Kompleks Kitosan Karbon Nanotube (Chito-CNt) Serta Pemanfaatannya Sebagai Agen Antibiotik. Prosiding Seminar Nasional Biologi UKSW, 20 Januari 2018.

Kolmas, J; Ewa, G; \& Dagmara, K R. 2014. Substitued Hydroxyapatite with Antibacterial Properties (Review). Hindawi Publishing Corporation, BioMed Research International, Vol.2014, Article ID: 178123, 15 pages.

Lamkhao, S; Manlika, P; Chutima, J; Nopakam, C; Kringkrai, T; Gobwute,
R; Phuwadol, B; \& Chamnan, R. 2018. Synthesis of Hydroxyapatit with Antibacterial Properties Using a Microwave-Assisted Combustion Method. Scinentific Reports (20019) 9:4014. https://doi.org/10.1038/s41598-01940488-8.

Nathanael, A J; D, Mangalaraj; \& S, I Hong. 2009. Biocompability and Antimicrobial Activity of Hydroxyapatite/Titania BioNanocomposite. $18^{\text {th }}$ International Conference on Composite Material.

Purnomo, H. 2014, Desain Molekul Antibiotika "Seri Penemuan Obat". Yogyakarta. Pustaka Pelajar. ISBN: 978-602-229-336-1.

Ragab, H S; F, A Ibrahim; F, Abdallah; Attieh, A Al-Ghamdi; Farid, ElTantawy; n, Radwan; \& F, Yakuphanoglu. 2014. Synthesis and In Vitro Antibacterial Properties of Hydroxyapatite Nanoparticles. IOSR Journal of Pharmacy and Biological Science (IOSR-JPBS) Vol.9 Issue 1, Ver.VI (Feb.2014), PP: 77-85. eISSN: 2278-3008; p-ISSN: 23197676.

Sudarmadji, S; Bambang, H; \& Suhardi. 2010. Prosedur Analisa untuk Bahan Makanan dan Pertanian. Yogyakarta. Liberty. ISBN: 979-499-227-5.

Sulaeman; Suparto; \& Evianti. 2005. Analisis Kimia Tanah, Tanaman, Air dan Pupuk. Bogor. Balai Penelitian Tanah Departemen Pertanian.

Suriawiria, U. 1993. Mikrobiologi Air dan Dasar-Dasar Pengolahan Buangan Secara Biologis. Bandung. Alumni. ISBN: 979-414-003-1.

Venkatesan, J: Rangasamy, J; Annapoorna, M; Ira, B \& Se-Kwon Kim. 2014. Antimicrobial Activity of ChitosanCarbon Nanotube Hydrogels. 
Materials 2014.7: 3946-3955. ISSN 1996-1944.

Wadu, I; Hartati, S; \& Margareta, N C. 2017. Karakterisasi Dan Uji Aktivitas Antibakteri Hidroksiapatit (HAp) Dari Kerabang Telur Ayam Terhadap Bakteri Lactobacillus acidophilus. JKPK UNS 2017.

Wang, S; Lena Ai ling, T; Qiaoliang, B; Ming Lin; Suzi, D; Bee Min, G \& Kian Ping
Loh. 2009. Room-Temperature Synthesis of Soluble Carbon Nanotubes by the Sonication of Graphen Oxide Nanosheets. National Univ of Singapore.

World Health Organization (WHO). 2017. Guidelines for Drinking-Water Quality: Fourth Edition. ISBN: 97892-4-154995-0. 